\title{
Über Oxydationen im Blut.
}

\author{
Von \\ Morizo Onaka (Japan).
}

(Aus der medizinischen Klinik in Heidelberg.)

(Der Redaktion zugegangen am 5. Februar 1911.)

Blut, den Gefäßen entnommen, zeigt eine geringe Sauerstoffzehrung. Die ersten Beobachtungen gehen auf Pflüger zurück und sind von den meisten Autoren qualitativ bestätigt worden, während in quantitativer Hinsicht die Versuchsresultate sehr bedeutend differieren. ${ }^{1}$ ) Über die Ursache der Sauerstoffzehrung herrschte eine gewisse Unsicherheit, indem die einen oxydable Substanzen, die andern die weißen Blutzellen oder Bakterien dafür verantwortlich machten. ${ }^{2}$ )

Vor einiger Zeit hat $\mathrm{W} \operatorname{arburg}^{3}$ ) gezeigt, daß die roten Blutzellen, die durch Waschen mit Salzlösungen vom Serum vollständig getrennt sind, unter Umständen eine deutlich meßbare Sauerstoffatmung haben; die Atmung schwankte in weiten Grenzen, teils war sie kaum meßbar, teils erreichte sie ziemlich erhebliche Werte; der Grund dafür wurde in dem verschiedenen Alter der Blutzellen gefunden, junge atmeten stark, alte sehr wenig. In guter Übereinstimmung hiermit fand Morawitz,4) daß die Sauerstoffzehrung bei experimentellen Anämien, wenn junge Elemente in den Kreislauf kommen, größer wird.

Gegen diese Atmung der Erythrocyten kam die Atmung

1) Vgl. Pflüger, Alex. Schmidt, Afonessiew, Zitate in Bohrs Referat in Nagels Handbuch.

2) So schreibt Bohr, loc. cit.: \&Wenn, wie in älteren Versuchen, der Stoffwechsel der Mikroben nicht gehemmt wird, so wird während des Auspumpens Sauerstoff in wechselnder Menge verbraucht und zwar unter sonst gleichen Umständen umsomehr, je länger das Auspumpen dauert.»

3) 0. Warburg, Zur Biologie der roten Blutzellen. Diese Zeitschrift, Bd. LIX, S. 112.

4) Schmiedebergs Archiv, Bd. LX, S. 298.

Hoppe-Seyler's Zeitschrift f. physiol. Chemie. LXXI. 
der Leukocyten, weil ihre Zahl unter den Versuchsbedingungen zu gering war, kaum in Betracht, Bakterien waren durch aseptisches Arbeiten ausgeschlossen und das Serum, wie erwähnt, durch Waschen entfernt, sodaß also in der Atmung der roten Blutzellen eine bisher nicht vermutete Ursache der Sauerstoffzehrung gefunden war. Da nun das Gesamtblut bei Gegenwart junger Erythrocyten auch entsprechend stärker atmet, so spielen jedenfalls Leukocyten und sauerstoffbindende Substanzen im normalen Blut keine Rolle.

Die älteren Versuche über Sauerstoffzehrung waren nicht immer an Blut angestellt, das besonders zahlreiche junge Erythrocyten enthielt, und somit schien die Frage nach der Ursache der Zehrung durch die Erythrocytenatmung nicht ausreichend erklärt. Herr Dr. Warburg hatte nun die Beobachtung gemacht, daß normales defibriniertes Blut bedeutend weniger atmete, als Blut, das in gerinnungshemmenden Mitteln aufgefangen war und dessen Blutplättchen noch erhalten waren; ich habe auf seine Anregung diese Beobachtung verfolgt und konnte wahrscheinlich machen, daß die Sauerstoffzehrung des normalen Blutes zum größeren Teil an die Intaktheit der Blutplättchen gebunden ist.

Hierdurch wird von neuem die Aufmerksamkeit auf jene von Bizzozero entdeckten Formelemente des Blutes gelenkt, die zuerst von Deetjen ${ }^{1}$ ) als selbständige Zellen aufgefaßt wurden und deren biologische Bedeutung zahlreiche Untersuchungen der letzten Jahre erwiesen haben; ich erinnere an ihre Rolle bei der Blutgerinnung, ${ }^{2}$ ) bei den Immunitätserscheinungen, ${ }^{3}$ ) und an ihren auffallend hohen Gehalt an proteolytischem Ferment. ${ }^{4}$ )

Methode.

Die Versuche wurden angestellt mit Blut vom Hund und Kaninchen. Den Sauerstoffverbrauch bestimmte ich mit Hilfe

1) Deetjen, Virchows Archiv, Bd. CLXIV.

2) Morawitz, Deutsches Archiv f. klin. Medizin, Bd. LXXIX (1904).

s) Gruber u. Futaki, Münchner med. Woch., Bd. LIV, S. 249.

4) Abderhalden u. Deetjen, Diese Zeitschrift, Bd. LIII (1907; 
des Haldane-Barcroftschen Wassermanometers in der von Warburg ${ }^{1}$ ) angegebenen Weise $(3 \mathrm{ccm}$ Ammoniaksaponinlösung; 1,8 ccm Blut): Die Temperatur während der Atmungsversuche war etwa $3^{\circ}$, die Versuchsdauer in der Regel 2 Stunden. Die Gerinnung verhinderte ich mit Hirudin, Natriummetaphosphat oder Natriumoxalat. Frisch bereitete Lösungen der betreffenden Stoffe wurden zu $1 \mathrm{ccm}$ gelöst, und das Blut bis zu einem Gesamtvolumen von $10 \mathrm{ccm}$ hinzugefügt. Die in den Tabellen angegebenen Zahlen sind die direkt beobachteten Druckverminderungen. (In den Tabellen in den mit «P überschriebenen Stäben angeführt.)

In den ersten Versuchen arbeitete ich stets mit maximal gesättigtem Blut, d. h. also mit Blut, das in einem offenen Gefäß ca. 10 Minuten geschüttelt worden war; eine Probe war durch Schütteln mit Glasperlen defibriniert, in der andern die Gerinnung verhindert. In dieser zweiten Probe wurde immer bedeutend mehr Sauerstoff verbraucht, doch waren die beobachteten Unterschiede wechselnde. Der Grund hierfür liegt, wenigstens teilweise, in der Behandlung des Blutes bei der Entnahme oder nach der Entnahme aus den Gefäßen, wie die folgenden Versuche zeigen; die Atmung ist so empfindlich, daß schon kurzdauerndes kräftiges Schütteln mit Glasperlen den Sauerstoffverbrauch sehr deutlich vermindert.

Tabelle I (Kaninchen).

\begin{tabular}{|c|c|c|c|c|c|c|c|}
\hline & \multirow{2}{*}{ Blut von A. carotis } & \multirow{2}{*}{$\begin{array}{l}\text { Zeit } \\
\text { Stun- } \\
\text { den }\end{array}$} & \multirow[b]{2}{*}{ V } & \multicolumn{3}{|c|}{$\mathrm{P}$} & \multirow[b]{2}{*}{$\mathrm{T}$} \\
\hline & & & & vor & nach & $\begin{array}{c}\text { Diffe- } \\
\text { renz }\end{array}$ & \\
\hline $\begin{array}{l}1 \\
2\end{array}$ & $\begin{array}{l}\text { Hirudinblut } \\
\text { Hirudinblut, geschüttelt }\end{array}$ & 2 & $\begin{array}{l}34,7 \\
35,7\end{array}$ & $\begin{array}{r}-5 \\
-4\end{array}$ & $\begin{array}{r}-20 \\
-5\end{array}$ & $\begin{array}{r}-15 \\
-1\end{array}$ & $17^{\circ}$ \\
\hline $\begin{array}{l}1 \\
2\end{array}$ & $\begin{array}{c}\text { Metaphosphatblut } \\
\text { Metaphosphatblut, geschüttelt }\end{array}$ & 2 & $\begin{array}{l}34,7 \\
35,9\end{array}$ & $\begin{array}{l}-4 \\
-2\end{array}$ & $\begin{array}{r}-15 \\
-7\end{array}$ & $\begin{array}{r}-11 \\
-\quad 5\end{array}$ & $17^{\circ}$ \\
\hline $\begin{array}{l}1 \\
2\end{array}$ & $\begin{array}{c}\text { Metaphosphatblut } \\
\text { Metaphosphatblut, geschüttelt }\end{array}$ & 2 & $\begin{array}{l}34,7 \\
35,7\end{array}$ & $\begin{array}{r}-10 \\
-3\end{array}$ & $\begin{array}{l}-30 \\
-10\end{array}$ & $\begin{array}{l}-20 \\
-7\end{array}$ & $16^{\circ}$ \\
\hline
\end{tabular}

1) Diese Zeitschrift, Bd. LXIX, S. 452. 
Für die Technik der Versuche ergibt sich daraus, daß starkes Schütteln, wie es zur maximalen Sättigung üblich ist, vermieden werden muß. Ich habe deshalb das Blut in dem Gefäß, in dem es aufgefangen wurde, durch vorsichtiges Rollen nur annähernd mit Sauerstoff gesättigt und immer vor dem Versuch, in $1,8 \mathrm{ccm}$, die Sauerstoffbindung gemessen. Aus der Differenz der Sauerstoffbindung nach dem Atmungsversuch und vor dem Atmungsversuch ergibt sich dann die verbrauchte Sauerstoffmenge. Auf diese Weise erhält man, beim Blut desselben Tieres, übereinstimmende Resultate. Als Beleg führe ich zwei Versuche an, in denen Blut aus der Carotis, das direkt verwendet wurde, und Blut aus der Vena jugularis, das in der beschriebenen Weise vorsichtig mit Sauerstoff beladen war, den gleichen Sauerstoffverbrauch zeigten.

Tabelle II (Kaninchen).

\begin{tabular}{|c|c|c|c|c|c|c|c|c|c|}
\hline & & & \multirow{2}{*}{$\begin{array}{c}\text { Zeit } \\
\text { Stun- } \\
\text { den }\end{array}$} & \multirow[b]{2}{*}{ V } & \multicolumn{3}{|c|}{$P$} & \multirow[b]{2}{*}{ T. } \\
\hline & & & & & & vor & nach & $\mid \begin{array}{l}\text { Diffe- } \\
\text { renz }\end{array}$ & \\
\hline $\begin{array}{r}\text { I } \\
\text { II }\end{array}$ & $\begin{array}{l}1 \\
2\end{array}$ & $\begin{array}{l}\text { V. jugularis } \\
\text { A. carotis }\end{array}$ & $\begin{array}{l}\left.\text { vor } 15 \text { Minuten } 0,1 \mathrm{~g}^{1}\right) \\
\text { Hirudin in } 10 \mathrm{ccm} \\
\text { NaCl-Lösung i. v. } \\
\text { eingespritzt }\end{array}$ & 2 & $\begin{array}{l}34,7 \\
35,7\end{array}$ & $\begin{array}{l}-4 \\
-4\end{array}$ & $\begin{array}{l}-20 \\
-18\end{array}$ & $\left|\begin{array}{l}-16 \\
-14\end{array}\right|$ & \\
\hline $\begin{array}{r}\text { I } \\
\text { II }\end{array}$ & $\begin{array}{l}1 \\
2\end{array}$ & $\begin{array}{l}\text { V. jugularis } \\
\text { A. carotis }\end{array}$ & Metaphosphatblut & 2 & $\begin{array}{l}34,7 \\
35,9\end{array}$ & $\begin{array}{l}-7 \\
-7\end{array}$ & $\begin{array}{l}-21 \\
-21\end{array}$ & $\left|\begin{array}{r}-14 \\
-14\end{array}\right|$ & 17 \\
\hline
\end{tabular}

Kaninchenblut.

Tabelle III.

\begin{tabular}{|c|c|c|c|c|c|c|c|c|c|}
\hline & & \multirow{2}{*}{$\begin{array}{l}\text { Blut von } \\
\text { A. carotis }\end{array}$} & \multirow{2}{*}{$\begin{array}{l}\text { Ver- } \\
\text { suchs- } \\
\text { dauer } \\
\text { Std. }\end{array}$} & \multirow[b]{2}{*}{ V. } & \multicolumn{3}{|c|}{$\mathrm{P}$} & \multirow[b]{2}{*}{ T. } & \multirow{2}{*}{$\begin{array}{c}\text { Leuko- } \\
\text { cyten- } \\
\text { zahl }\end{array}$} \\
\hline & & & & & vor & nach & $\begin{array}{c}\text { Diffe- } \\
\text { renz }\end{array}$ & & \\
\hline \multirow{3}{*}{ I } & 1 & Hirudinblut & \multirow{3}{*}{2} & 35,9 & -3 & -21 & -18 & \multirow{3}{*}{$17^{\circ}$} & - \\
\hline & 2 & Metaphosphatblut & & 34,7 & -3 & -21 & -18 & & 一 \\
\hline & 3 & defibriniertes Blut & & 35,7 & - & -5 & -5 & & 一 \\
\hline \multirow{2}{*}{ II } & 1 & Metaphosphatblut & \multirow{2}{*}{2} & 35,7 & -4 & -16 & -12 & \multirow{2}{*}{$17^{\circ}$} & - \\
\hline & 2 & defibriniertes Blut & & 35,9 & -2 & $-\dot{b}$ & -3 & & - \\
\hline
\end{tabular}

1) Gerinnungshemmung sintra vitam *. 
Tabelle III. - Fortsetzung.

\begin{tabular}{|c|c|c|c|c|c|c|c|c|c|}
\hline & & \multirow{2}{*}{$\begin{array}{l}\text { Blut von } \\
\text { A. carotis }\end{array}$} & \multirow{2}{*}{$\begin{array}{l}\text { Ver- } \\
\text { suchs- } \\
\text { dauer } \\
\text { Std. }\end{array}$} & \multirow{2}{*}{ V. } & \multicolumn{3}{|c|}{$P$} & \multirow{2}{*}{ T. } & \multirow{2}{*}{$\begin{array}{l}\text { Leuko- } \\
\text { cyten- } \\
\text { zahl }\end{array}$} \\
\hline & & & & & vor & nach & $\begin{array}{l}\text { Diffe- } \\
\text { renz }\end{array}$ & & \\
\hline \multirow{3}{*}{ III } & 1 & Metaphosphatblut & \multirow{3}{*}{2} & 34,7 & -4 & -21 & -17 & \multirow{3}{*}{$15^{\circ}$} & - \\
\hline & 2 & $\begin{array}{c}\text { defibriniertes } \\
\text { Metaphosphatblut }\end{array}$ & & $3 \check{5}, 9$ & -1 & -10 & -9 & & - \\
\hline & 3 & defibriniertes Blut & & 35,9 & -3 & -10 & -7 & & - \\
\hline \multirow[t]{2}{*}{ IV } & 1 & Metaphosphatblut & \multirow[t]{2}{*}{2} & 34,7 & -7 & -23 & -16 & \multirow[t]{2}{*}{$16^{\circ}$} & - \\
\hline & 2 & defibriniertes Blut | & & 35,9 & -2 & -5 & -3 & & 一 \\
\hline \multirow{3}{*}{ V } & 1 & Oxalatblut & \multirow{3}{*}{2} & 34,7 & -4 & -17 & -13 & \multirow{3}{*}{$16^{\circ}$} & 6400 \\
\hline & 2 & $\begin{array}{l}\text { defibriniertes } \\
\text { Oxalatblut }\end{array}$ & & 35,7 & -2 & -3 & -1 & & 4200 \\
\hline & 3 & $\mid$ defibriniertes Blut $\mid$ & & 35,9 & -3 & -5 & $-2 \mid$ & & \\
\hline \multirow{3}{*}{ VI } & 1 & Oxalatblut & \multirow{3}{*}{2} & 34,7 & -4 & -18 & -14 & \multirow{3}{*}{$17^{\circ}$} & 4500 \\
\hline & 2 & $\begin{array}{c}\text { defibriniertes } \\
\text { Oxalatblut }\end{array}$ & & 35,2 & -1 & -7 & -6 & & \multirow[t]{2}{*}{3500} \\
\hline & 3 & defibriniertes Blut & & 35,9 & -2 & -6 & -4 & & \\
\hline
\end{tabular}

Aus den Zahlen geht hervor, daß der Sauerstoffverbrauch des Blutes, dessen Gerinnung verhindert wurde, den des defibrinierten Blutes um ein Mehrfaches übertrifft (das Dreibis Fünffache; genauere Angaben haben keine Bedeutung, weil der Fehler etwa $2 \mathrm{~mm}$ : beträgt). Die gerinnungshemmenden Mittel beeinflussen den Sauerstoffverbrauch direkt in keiner Weise; denn Metaphosphat oder Natriumoxalat, in gleichen Mengen zum defibriniertenBlut zugesetzt, steigerten die Atmung nicht (in der Tabelle bezeichnet als «defibriniertes Metaphosphatblut», «defibriniertes Oxalatblut").

Beim Defibrinieren durch Schütteln mit Glasperlen geht immer ein Teil der Leukocyten verloren, und es war daran zu denken, daß die beobachteten Differenzen mit der Verminderung der Leukocytenzahl zusammenhingen. In Versuch 5 und 6 habe ich die Leukocyten im Oxalatblut und im defibrinierten Blut gezählt, wobei sich ergab, daß die Leukocytenzahlen auch nicht entfernt im Verhältnis des Sauerstoffverbrauchs stehen. Es ist darnach ungemein unwahrscheinlich, daß die beobachteten Differenzen auf Unterschiede in der Leuko- 
cytenzahl zurückzuführen sind, man müßte denn annehmen, daß ein kleiner Teil der Leukocyten im Verhältnis zu den übrigen enorm stark atmet und daß gerade diese starkatmenden Leukocyten beim Defibrinieren in dem Fibrinnetz zurückgehalten werden.

Weiterhin war daran zu denken, daß aus einem unbekannten Grund im Plasma noch Oxydationen vor sich gehen könnten, die im Serum fehlten. Diese Vermutung hat sich nicht bestätigt; ich konnte nachweisen, daß die sauerstoffzehrenden Stoffe des Plasmas sich zentrifugieren lassen, daß es sich also offenbar um atmende Formelemente handelt. In der folgenden Versuchsanordnung wird das deutlich :

Hunden wurde, in der Morphiumnarkose, aus der Arteria femoralis oder Carotis, Blut entnommen, das aus der Kanüle direkt in Metaphosphat floß (4 ccm einer 10\% igen Lösung auf $20 \mathrm{ccm}$ Blut), dann wurde fraktioniert zentrifugiert in der von Morawitz ${ }^{1}$ ) beschriebenen Weise und zwar zuerst kurz, um die Hauptmenge der weißen Blutzellen und die roten Blutzellen abzuschleudern; dann länger und stärker, um die Hauptmenge der Blutplättchen abzuschleudern (Fraktion A), schließlich ein drittes Mal, um den Rest der Blutplättchen (Fraktion B) und klares zellfreies Plasma zu gewinnen. Es wurden nun in 3 Gläschen von $3 \mathrm{ccm}$ Inhalt je $0,8 \mathrm{ccm}$ des ersten konzentrierten Zentrifugats (rote und weiße Blutzellen) gebracht, darauf das erste Gläschen mit Zentrifugat $A$, das zweite mit Zentrifugat $B$, das dritte mit zellfreiem Plasma angefüllt. Die 3 Proben unterschieden sich also ganz vorwiegend durch ihren Gehalt an Blutplättchen.

\begin{tabular}{lcc} 
& \multicolumn{2}{c}{ Sauerstofferbrauch ${ }^{2}$ ) } \\
& Versuch I & Versuch II \\
Fraktion A & 30 & 29 \\
Fraktion B & 19 & 14 \\
Zellfreies Plasma & 4 & 9
\end{tabular}

1) Morawitz, Beiträge zur Kenhtnis der Blutgerinnung. Deutsches Archiv f. klinische Medizin, Bd. LXXIX, S. 215. - Schittenhelm und Bodeng, Archiv f. exp. Pathologie u. Pharmakologie, Bd. LIV, S. 217.

2) Abgelesene Druckverminderungen, die $1,8 \mathrm{~cm}$ Blut bei $16^{\circ} \mathrm{er}-$ gaben. $\mathbf{v}=$ ca. 36 . Atmung bei $38^{\circ} 2$ Stunden. 
Aus diesen Zahlen ergibt sich, daß die Atmung im Blut, dessen Gerinnung verhindert ist, offenbar zum größten Teil auf die Blutplättchen zu beziehen ist. Dieser Schluß war von vornherein sehr naheliegend, da man weiß, in wie engem Zusammenhang die Gerinnung mit dem Zerfall der Blutplättchen steht. ${ }^{1}$ ) Allerdings läßt sich die Atmung des Plasmas nicht etwa so konzentrieren, wie man aus der relativen Vermehrung der Blutplättchen im Zentrifugat erwarten sollte. Ich erkläre das durch eine Schädigung der Bluttplättchen beim Zentrifugieren, da wir teils durch frühere Untersuchungen, teils durch die erwähnten Schüttelversuche wissen, wie empfindlich die Blutplättchen gegen mechanische Insulte sind. Der geringe Sauerstoffverbrauch in den Gläschen mit zellfreiem Plasma ist ohne Schwierigkeit auf die Atmung der roten und weißen Blutzellen zurückzuführen.

1) Deetjen, Zerfall und Leben der Blutplättchen. Diese Zeitschrift, Bd. LXIII, S. 1. 